\title{
Change Agent 007 - Licence to Simulate
}

\author{
Matleena Pankakoski \\ Department of Industrial Engineering and Management, Helsinki University of Technology
}

E-mail: matleena.pankakoski@hut.fi

Key words: game facilitation, tailored simulation game, training programme, work process development

\begin{abstract}
This paper deals with the role and actions of internal change agents as game facilitators. The paper describes a training programme called SIMNET for training new game facilitators to use a work process development method called the Work Flow Game. The Work Flow Game is an action-oriented, tailored simulation game where the participants simulate their own real work activities together. There were eleven internal change agents from nine different organisations participating in the training programme. The results of the training programme were evaluated by conducting a qualitative case study. All participants were able to carry out their simulation games and most of the projects gained results in terms of implementation of changes.
\end{abstract}

\section{INTRODUCTION}

This article aims at contributing to the less studied topic of the role of internal change agents as game facilitators. Hartley et al. $(1997,62)$ state that while there is a small amount of literature about the role of consultants and change agents acting as external change agents or catalysts for an organisation, the literature is less informative about those who try to develop change from within the organisation. Furthermore, the existing literature has tended to produce idealised lists of skills rather than actual roles, activities and performance of change agents in practice. This paper describes a 
training programme for training new game facilitators as well as the role and actions of game facilitators using a process development method called the Work Flow Game. Apart from the introspective account of Piispanen (1995), the subject has not received much attention in the earlier research on the Work Flow Game or corresponding social simulation games.

Firstly, the Work Flow Game method is introduced. Secondly, the role of the game facilitator is discussed. Thirdly, a training programme called SIMNET for training internal change agents to become game facilitators is described. Finally, the facilitation experiences and some results of the first SIMNET programme are summarised.

\section{THE WORK FLOW GAME}

The Work Flow Game is a simulation game combining the features of simulation with those of a game. The Work Flow Game is based on a simplified model of the selected work process, which will be simulated in accelerated time during the game session. It is an action-oriented simulation, where the participants simulate their own real work activities together. It also has the features of a game, e. g. roles, rules and game material. (Ruohomäki 1994; 1995). In the Work Flow Game, three key factors of organisation development are combined: improving (or re-engineering) work processes, experiential learning and participative design. It is always a part of a larger development project and can be used in different phases of the change process. It can be utilised at the beginning of a development project to start change and to localise problems, or later on, to test and practise new ways of action. There can be several rounds, first a game to describe the current status and later on a "vision game" when the new operational model is tested. (Ruohomäki 1994; 1995.)

The experiences from the reported WFG cases in knowledge work (see e.g. Piispanen et al. 1996, Ruohomäki 1994, 1995, Piispanen 1995) and several studies in the production management branch (e.g. Forssén-Nyberg \& Kutilainen 1998, Haho 1998, Smeds 1996), have proved the method beneficial in terms of presenting the work process as a whole, revealing the development needs and opportunities, motivating people for change through active participation, and promoting the interactive learning of the participants. Co-operation, communication and general working atmosphere have often improved after the game day. Long-term effects of process development can be seen in better productivity and quality of the work process (e.g. streamlining the process, less rework) as well as in improved customer service in terms of delivery accuracy, production flexibility and shorter lead times. 
The Work Flow Game method consists of three parts: 1) planning the game, 2) the game day, and 3) debriefing and development activities after the game session. (Piispanen et al. 1996.) The planning phase is usually carried out by a team representing different parts of the work process. The project team works with the assistance of a game facilitator. For the Work Flow Game, a cross-functional work process is selected as the object of the development. The Work Flow Game is based on a real, typical case example representing the selected work process. In the planning phase, work processes are analysed and modelled, the case example is selected, a manuscript is prepared for the game session, members of the organisation are briefed, and concrete preparations are made for the game day. (Piispanen et al. 1996.)

The game day consists of the game session and debriefing. During the game session, the participants of the Work Flow Game are seated in a circle, which forms the game setting. There are two types of participants in the simulation game: players and observers. The players are all those employees, managers and customers who have participated in the selected case example in reality. The players have their real professional roles in the simulation. They talk aloud about what they do, how they perform their tasks, which equipment and documents they use, what kinds of problems occur, and who the next person is that they contact or send the documents to. The observers' task is to follow the game events and make notes about problems like bottlenecks and unnecessary repetition as well as improvement ideas they have observed. The game facilitator sees that the process goes according to the manuscript and timetable. After the game session, there is an intensive debriefing organised in small groups and general discussions. The development work will continue several months after the game day, depending on the development needs of the work process. (Piispanen et al. 1996.)

\section{GAME FACILITATOR'S ROLE}

The role of the game facilitator is crucial both in the planning phase of the game and during the game day. The way of facilitating as well as the facilitator's knowledge, skills and attitudes have an influence on the success of the game and achieving the set targets. (Greenblat \& Duke 1981.) The role of the game facilitator can be analysed by comparing it to different modes of consultation (Figure 1). The grid depicts whether the consultant has expertise of a particular content area from the viewpoint of the customer, or whether (s)he is a pure process consultant, i.e. a person who "helps the client perceive, understand and act upon the process events that occur in the 
client's environment" (Schein 1987, 34), and how much responsibility the consultant takes for directing the process.

\section{Directive}

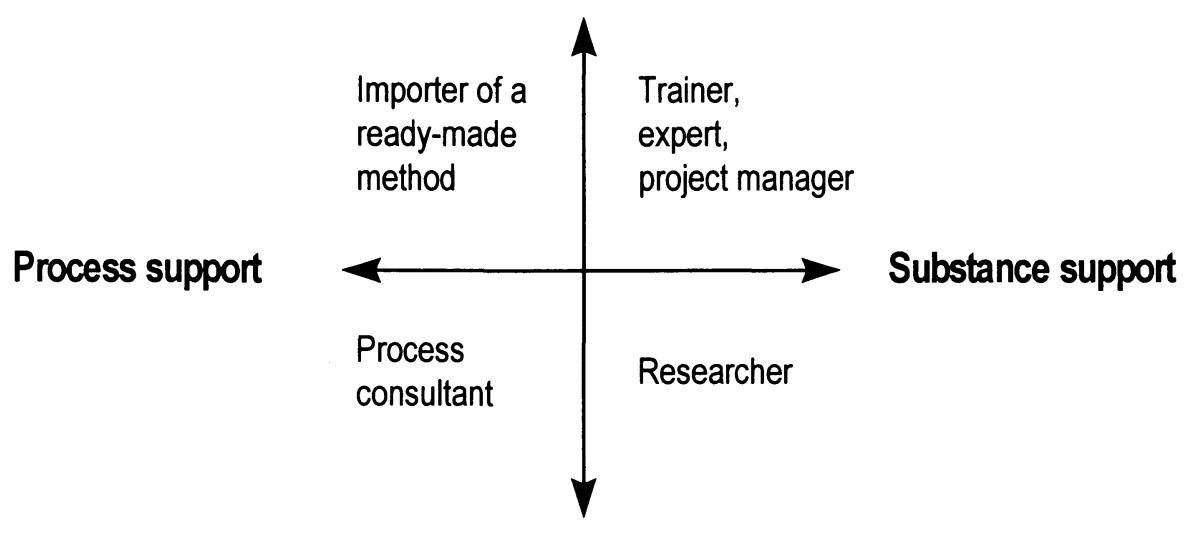

Non-directive

Figure 1. The role dimensions of consultancy (Piispanen \& Ylisuvanto 1993).

Here the word "game facilitator" is used on purpose instead of "game leader". In the game situation the facilitator usually acts as the game leader, but in the broad sense (s)he is supposed to facilitate the whole change process, which is different from being a directive project manager. The task of the facilitator is to act as a supporting person, who helps the members of the organisation plan the game and activates the players to study their own work practices. (Piispanen et al. 1998). The role of the game facilitator resembles the role definition by Knowles (1975), as he describes the new role of a teacher of adults moving from content transmitter to facilitator of learning.

The game facilitator can be an external or internal consultant, change agent or researcher. An external facilitator has more clearly the role of a process consultant, bringing new tools, concepts and models to the process. If the external facilitator is too directive, there is a danger that the participants adopt a passive role, become too dependent on the facilitator, and will not take responsibility for implementing the improvement ideas after the game day. (Piispanen et al. 1998.) If an external consultant facilitates the Work Flow Game, a content expert from inside the organisation is needed to take the responsibility for substance matters. Often the best combination is to have one person who knows the method and another who owns the process working together. An internal change agent may work either in the expert or process consultant role. The decisive factor 
is whether (s)he is developing a process in her or his own work context or somewhere else in the organisation. The role of the internal game facilitator may, however, be more directive, because it is possible that (s)he is the game facilitator and the person responsible for the development project at the same time.

The facilitator is responsible for creating a mutually trustful and positive atmosphere so that the participants can join the game day without hesitations. The facilitator sees that the game proceeds according to the manuscript and the game rules, and that the focus remains on the process as a whole, not on personalities. It is the responsibility of the facilitator to estimate when a game can be entered and whether the organisation has the capability to deal with the themes that come up during the game. If the personnel feel the game is too threatening or has hidden agendas, the facilitator must know when to stop in time. (Piispanen et al. 1998) The social learning environment resembles in many respects the one described by Knowles (1984), as he emphasises e.g. supportive learning climate, mutual respect, trust, openness, and co-operation as basic social factors of the learning process.

The use of methods like the Work Flow Game has been typically based on individual development projects, in which an outside consultant or researcher has acted as a change agent and the methodological expert. As a consequence, spreading of methodological competencies and extensive utilisation of the methods have been slow, and the development work has usually focused only on certain restricted areas within the organisation. However, it does not have to be an exclusive right of consultants and researchers to use what are called expert methods in order to develop work organisations. Dissemination of development methods and other organisational innovations is not only necessary but also possible as there are growing numbers of highly educated and skilled practitioners who are able to carry out organisation development projects if only they have relevant methods to work with.

However, one has to bear in mind that getting started with a development project, describing work processes, facilitating learning, and implementing the development ideas, require similar user competencies (Alänge et al. 1998) to those required in any development project, independent of the methods used. This notion is crucial in terms of disseminating and applying the Work Flow Game: learning to facilitate a simulation game like this is not just a collection of easy-to-learn tricks, but a way of developing that requires a holistic approach to organisation development. So it is mainly explicit knowledge and practical skills, i.e. relatively surface competencies that can be developed through training. 


\section{SIMNET TRAINING PROGRAMME}

In order to train new Work Flow Game facilitators for Finnish work organisations, a new training programme, called SIMNET, was planned according to the seven phases of the Work Flow Game method (cf. Figure 2). The programme is carried out by the Laboratory of Work Psychology and Leadership at the Helsinki University of Technology. The training is designed for internal consultants, trainers, people responsible for quality improvement, and line managers/process owners, i.e. persons responsible for carrying out development activities. The participants are supported by the training programme; they are responsible for carrying out their development processes in their organisations without outside consultants. After facilitating their first simulation games, the participants are given a certificate that indicates that they are "licensed" Work Flow Game facilitators.

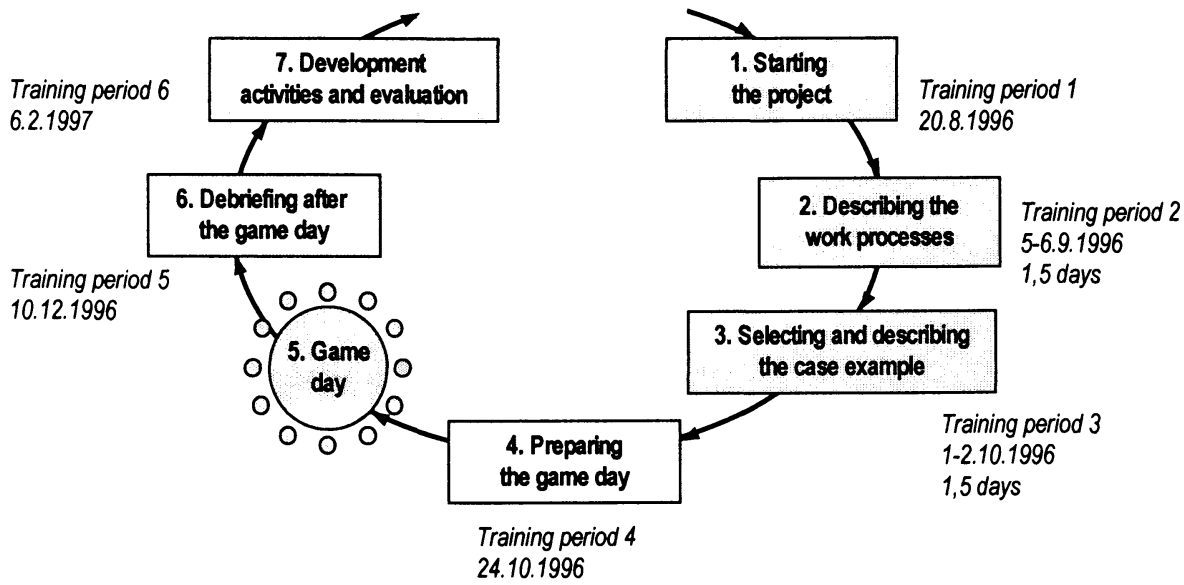

Figure 2. The timetable of the first SIMNET training programme in relation to the phases of the method.

The application of the Work Flow Game is taught during the training periods. The training periods are always followed by fieldwork in participating organisations so that the theory can be put into practice immediately. In each training period, there are learning tasks that are started together and then given as homework for the participants to be completed during the fieldwork period. The idea of the learning tasks is to support and direct the development projects.

The following elements are included in each training period: lectures and case examples, short presentations of the participants, general discussions and sharing experiences, guidance of the participants, (group) working on the current phase of the planning process, and giving learning tasks for the 
field period. The programme represents an open action learning type of learning environment (cf. Revans 1982) as a contrast to traditional short courses. The basic idea is to apply the acquired knowledge and skills immediately instead of learning the basics in theory only.

\section{FACILITATION EXPERIENCES}

In the first SIMNET training programme ${ }^{1}$, there were eleven participants from nine different organisations representing both the public and private sectors. Both professional developers and people with operative responsibilities or expert position acted as game facilitators. Seven of the participants were working as internal consultants or had an official role in organisation development activities; four of them were already very experienced developers. The other participants had at least participated in development projects or conducted them within their own work units. Two participants worked as line managers.

The evaluation of the first SIMNET training programme was carried out by conducting a descriptive, qualitative, embedded case study (Gummesson 1991). The data consisted of semi-structured interviews, questionnaires with multiple choice and open-ended questions as well as document material about the organisations and simulation games of the trainees. The data were collected throughout the training programme and also during a $11 / 4$ years follow-up period. The aim of the follow-up period was to study the independent application of the Work Flow Game method after the first simulation games during the training programme. In this paper, the results of the first SIMNET training programme are summed up. The facilitation experiences of the internal change agents, i.e. the trainees, are illustrated by giving a few examples and authentic quotations.

All game facilitators were able to carry out their games and most of the projects gained results in terms of implementation of changes. The game facilitators were satisfied with their game days and felt they had succeeded well in facilitating the games. From the methodological point of view, the game facilitators were able to tailor the method according to their own needs. Some of them even developed new innovative methodological solutions in terms of the roles of the players and visualising the game events. The method was also used for new purposes, such as team development. From the viewpoint of achieving development results, the best case was one

1 From July 1996 to August 1999, there have been four SIMNET training programmes having 40 participants from 28 different organisations. In addition, there have been two organisation-specific training programmes, in which 12 game facilitators have been trained. The SIMNET project continues till the end of 1999. For a more detailed account of the theoretical basis and results of the first training programme, see Pankakoski 1998. 
where there was a representative of the management taking the ultimate responsibility for the implementation phase and even more, if the game facilitator was able to continue supporting the development for some time after the game day.

The game facilitators felt that the game could well be used internally without outside consultants. However, there were some differing opinions about the difficulty of developing different kinds of processes. One game facilitator was worried about starting a new project in an area she was not familiar with, whereas another facilitator thought there might be some difficulties when facilitating the game within one's own area.

"For me this was easy because I was familiar with all the processes in advance. It was easy to start to play something I already knew. I'm quite familiar with the entire financial administration. But now that I'm leaving the department, it has been suggested that I should go to the editorial office and facilitate a game there, that does give me the heebie-jeebies; my god, after all I don't know anything about editing a magazine. When you have to start from the bottom, it surely is a more difficult situation..."

"If we were to simulate the process of employing someone or recruiting a new person to the company, processes that include some of my own work tasks, and I would facilitate a game like that I wonder how it would work... You are an expert in your own process but you also look at it from a certain perspective and you will not necessarily see all the possibilities to develop it when you already have a certain model or habit in your head."

In three cases where the game facilitators were members of the work community in which they conducted the game, there were some extra pressures to succeed. They felt that failing was no option for them; an outside consultant always leaves the work organisation behind, but a member of the work community still has to live with the situation after the development project. In other cases that was not a problem, because the game facilitators had already established their position as internal consultants; and moreover, they did not carry out the Work Flow Games within their own organisational units. The internal consultants had perhaps the easiest situation, because they were always working outside their own units but still knew the organisation, its values, norms, and people.

"Especially when there are familiar co-workers there is a different tension in the air than when you go to an unfamiliar organisation. The familiarity creates a different kind of tension. I certainly had butterflies in my stomach... You have to succeed in front of your own people. An external professional consultant automatically receives respect that is not easily shown to an internal one."

"And an internal consultant, he really knows the organisation, knows all the systems; that brings a lot of advantages ... However, if we sent our 
departmental managers as consultants to other departments it could create problems. However, the fact that we all work in kind of personnel units or not within the same organisation and we do not have line responsibility makes everything much easier because in a case like this you only act as support and assist in leading the project. It's more neutral that way."

In terms of continuous use of the method after the training programme, the user's position for development could be found to be important. The professional developers/internal consultants were most likely to continue using the method. Starting a new game was easier, if the game facilitator had a legitimate position for development as a professional developer.

The main reasons for continuous use of the method after the training were related to the following factors: strong management support in terms of allocating resources for development, enthusiastic personnel, development culture that was based on process-thinking and participative development, the need for using methods based on co-operative learning and process analysis, as well as positive experiences from the first Work Flow Games.

The reasons for not continuing the use of the method after the training were related either to the game facilitator or the prevailing situation in the organisation. Some game facilitators had moved to another position or organisation, or were lacking a legitimate role as internal change agents without any allocated working hours for development projects. The organisational reasons concerned major organisational reorganisations or other simultaneous change processes competing for the same limited resources.

\section{CONCLUSIONS AND DISCUSSION}

In the future, more attention should be paid to choosing participants for training programmes such as SIMNET. Firstly, the persons who are supposed to apply new methods independently should have both former development experience and a legitimate role to carry out organisational development processes. Secondly, there should not be too many simultaneous changes going on in the organisation if a new method requiring quite a lot of resources is to be introduced. The critical success factors of any change project also apply to development projects in which the Work Flow Game is used (cf. e.g. Kotter 1995). Third, it is important that applying the method is not only a practical exercise for the participant, but the work community in which the method is applied has a real need and motivation for using the method and taking responsibility for implementation of changes. It is not enough only to simulate things. Improvements are not realised until they are implemented in real life. 
Despite the observation that the method can be learnt and used by internal change agents without outside consultants in the organisation, there are certain advantages of having an experienced external game facilitator carrying out the first Work Flow Game. By following the actions of an experienced facilitator, much more than just the external forms of the method can be learnt and passed on. Many important tacit elements of the method are lost when the knowledge is packed in the codified form to be communicated via a handbook or a training programme. The necessary tacit knowledge is embedded and recreated in the action of those who apply the method. Moreover, the training model is not suitable for all organisations. There are organisations in which the facility for self-directed development is not yet at such a level that development activities could be carried out without outside consultancy. In some cases the culture or the present situation in the organisation requires an outside change agent to support the development work, because an outside person perhaps has a more neutral position than an internal change agent.

\section{REFERENCES}

Alänge, S., Jacobsson, S. \& Jarnehammar, A. (1998) Some Aspects of an Analytical Framework for Studying the Diffusion of Organizational Innovations. Technology Analysis \& Strategic Management, Vol. 10, No. 1, 3-21.

Forssén-Nyberg, M. \& Kutilainen, P. (1998) Participative simulation game as facilitator of organizational development process - two case studies. In: Smeds, R. \& Riis, J. O. (Eds.) Experimental Learning in Production Management, The effects of using simulation games in universities and industry, 39-49. Chapman \& Hall, London

Greenblat, C. S. \& Duke, R. D. (Eds.) (1981) Principles and practices of gaming-simulation. Sage, London.

Gummesson, E. (1991) Qualitative Methods in Management Research. Sage, Newbury Park.

Haho, P. (1998) Tailored simulation games for successful business process development. In: Smeds, R. \& Riis, J. O. (Eds.) Experimental Learning in Production Management, The effects of using simulation games in universities and industry, 24-38. Chapman \& Hall, London.

Hartley, J., Benington, J. \& Binns, P. (1997) Researching the Roles of Internal Change Agents in the Management of Organizational Change. British Journal of Management, Vol. 8, 6173.

Knowles, M. S. (1975) Self-directed learning, a guide for learners and teachers. Association Press, Chicago.

Knowles, M. S. (1984) Andragogy in Action. Applying modern Principles of Adult Learning. Jossey-Bass Publishers, San Francisco, London.

Kotter, J. P. (1995) Leading Change: Why Transformation Efforts Fail. Harvard Business Review, March-April 1995, 59-67.

Pankakoski, M. (1998) Knowledge Sharing and Value Reproduction - The Work Flow Game as a Case Example. Docotral dissertation. Helsinki University of Technology, Industrial 
Management and Work and Organizational Psychology, Report No 6. Hakapaino, Helsinki.

Piispanen, E. (1995) Simulaatiopeli muutoksen käynnistäjänä. Esimerkkitapaus Turun ja Porin lääninhallituksesta. Tuottavuudella tulevaisuuteen. Hallinto- ja toimistotyö organisaation tuottavuustekijänä (Keto) -projektin julkaisuja, Espoo. (The simulation game starts the change process. Case example from a Provincial Government of Turku and Pori. Report of the Productive Office (Proffice) project. The Finnish National Productivity Programme. Espoo: Otapaino.) (in Finnish)

Piispanen, E., Ruohomäki, V., Pankakoski, M. \& Teikari, V. (1996) The Work Flow Game A new method for developing office work. In: Saunders, D., Percival, F. \& Vartiainen, M. (Eds.) The Simulation and Gaming Yearbook, Vol 4: Games and Simulations to Enhance Quality Learning. Kogan Page, London.

Piispanen, E., Pankakoski, M., Ruohomäki, V., \& Teikari, V. (1998) The Work Flow Game for Knowledge Work. A Handbook. Hakapaino, Helsinki.

Piispanen, E. \& Ylisuvanto, E. (1993) Miten arvioida konsultointityötä? Konsulttien roolivalinnat ja hankkeiden tuloksellisuus (How to evaluate consultancy? The roles of consultants and effectiveness of the projects). Seminar report for POHTO's consultant training programme. Unpublished report. The Finnish Institute of Public Management, Helsinki. (in Finnish)

Revans, R. W. (1982) The origins and growth of action learning. Studentlitteratur, Lund.

Ruohomäki, V. (1994) Simulation games and their effects - the Work Flow Game for the development of administrative work. Helsinki University of Technology, Industrial Economics and Industrial Psychology, Report No 156, Espoo.

Ruohomäki, V. (1995) A simulation game for the development of administrative work processes. In: Saunders, D. (Ed.) The Simulation \& Gaming Yearbook 1995, Vol 3. Kogan Page, London, 264-270.

Schein, E. H. (1987) Process Consultation, Volume II, Lessons for Managers and Consultants. Addison-Wesley.

Smeds, R. (1996) Management of Enterprise Evolution. Evolution Management Principles and Methods for Learning Organizations. Acta Polytechnica Scandinavica, Mathematics, computing, and management in engineering series, No 80, Helsinki.

\section{ACKNOWLEDGEMENTS}

The data on which this paper is based on has been collected as part of SIMNET project under the Finnish National Productivity Programme. The SIMNET training programme as well as the data collection have been carried out by a multidisciplinary research group. The former and present members of the group - former project manager Eeva Piispanen, researchers Marjatta Komulainen and Heini Ikävalko, and professor Veikko Teikari are given special acknowledgements for all their valuable contribution.

The research is financially supported by the following organisations which are gratefully acknowledged: the Academy of Finland, the Ministry of Labour, the Emil Aaltonen foundation, as well as the nine Finnish work organisations that participated in the SIMNET training programme. 


\section{BIOGRAPHY}

\section{Matleena Pankakoski}

Matleena Pankakoski works at the Helsinki University of Technology at the Department of Industrial Engineering and Management. She is the project manager of two research projects, SIMNET and Team Measures, which are part of the Finnish National Productivity Programme. Her doctoral dissertation dealt with knowledge sharing and innovation diffusion, using the Work Flow Game as a case example. Her other research areas concern team and work process development, knowledge management and commercialisation, and learning at work. 